This series is published by the

University of Oslo Department of Economics

P. O.Box 1095 Blindern N-0317 OSLO Norway

Telephone: + 4722855127

Fax: $\quad+4722855035$

Internet: http://www.sv.uio.no/econ

e-mail: $\quad$ econdep@econ.uio.no
In co-operation with

The Frisch Centre for Economic Research

Gaustadalleén 21

N-0371 OSLO Norway

Telephone: $\quad$ +4722958820

Fax: $\quad+4722958825$

Internet: http://www.frisch.uio.no

e-mail: $\quad$ frisch@ frisch.uio.no

\section{Last 10 Memoranda}

\begin{tabular}{|c|c|}
\hline No $06 / 17$ & $\begin{array}{l}\text { Eva Kløve and Halvor Mehlum } \\
\text { The Firm and the self-enforcing dynamics of crime and protection }\end{array}$ \\
\hline No $05 / 17$ & $\begin{array}{l}\text { Halvor Mehlum } \\
\text { A polar confidence curve applied to Fieller's ratios }\end{array}$ \\
\hline No $04 / 17$ & $\begin{array}{l}\text { Erik Biørn } \\
\text { Revisiting, from a Frischian point of view, the relationship between } \\
\text { elasticities of intratemporal and intertemporal substitution }\end{array}$ \\
\hline No $03 / 17$ & $\begin{array}{l}\text { Jon Vislie } \\
\text { Resource Extraction and Uncertain Tipping Points }\end{array}$ \\
\hline No $02 / 17$ & $\begin{array}{l}\text { Wiji Arulampalam, Michael P. Devereux and Federica Liberini } \\
\text { Taxes and the Location of Targets }\end{array}$ \\
\hline No $01 / 17$ & $\begin{array}{l}\text { Erik Biørn } \\
\text { Identification and Method of Moments Estimation in Polynomial } \\
\text { Measurement Error Models }\end{array}$ \\
\hline No $19 / 16$ & $\begin{array}{l}\text { Erik Biørn } \\
\text { Panel data estimators and aggregation }\end{array}$ \\
\hline No $18 / 16$ & $\begin{array}{l}\text { Olav Bjerkholt } \\
\text { Wassily Leontief and the discovery of the input-output approach }\end{array}$ \\
\hline No $17 / 16$ & $\begin{array}{l}\text { Øystein Kravdal } \\
\text { New Evidence about effects of reproductive variables on child mortality in } \\
\text { sub-Saharan Africa }\end{array}$ \\
\hline No $16 / 16$ & $\begin{array}{l}\text { Moti Michaeli and Daniel Spiro } \\
\text { The dynamics of revolutions }\end{array}$ \\
\hline
\end{tabular}

Previous issues of the memo-series are available in a PDF® format at: http://www.sv.uio.no/econ/english/research/unpublished-works/working-papers/ 


\title{
Positive illusions and the temptation to borrow.
}

\author{
Eva Kløve Halvor Mehlum
}

\begin{abstract}
We provide an explanation of the low willingness to save that is observed in many poor countries. Our explanation is based on the hypothesis that people have an over-optimistic outlook. As discussed in the psychological literature, an illusionary positive view of the future may be a good thing. However, we show that it can lead individuals to accumulate unsustainable levels of debt. Using survey data from South Africa, we confirm that poor people are indeed overly optimistic, and also that optimism is positively and significantly related to debt accumulation.
\end{abstract}

JEL: D03, D14, O1, O12

Keywords: poverty, savings, discounting, debt 


\section{Introduction}

Surveys and experimental data from developing countries show over and over again that poor people are reluctant to save ${ }^{1}$. The explanations provided in the literature have been many and several are based on behavioural economic models. The straight forward explanation is that people generally place low value on the future. A variant of this builds on hyperbolic discounting preferences, i.e. that people are impatient today but that they are more patient with the future the further away it is. In other words, the discount rate varies inversely with the length of waiting time. ${ }^{2}$ Another explanation is lack of self-control, which happens as a result of discount rates that vary inversely with the size of the reward for which the individual must wait (Thaler 1981). All these factors lead people to spend today rather than saving for tomorrow.

In this article we provide a supplementing explanation based on positive illusions about future prospects. The low willingness to save may not only be related to the discount rate. It is equally compatible with an optimistic outlook. The argument expands on Frederick, Loewenstein \& O'donoghue (2002) who discuss the many difficulties in measuring discount rates. For example, "[a] reward of $\$ 100$ now might also generate more utility than the same amount five years hence because a person expects to have a larger baseline consumption level in five years (e.g. due to increased wealth). As a result, the marginal utility generated by an additional $\$ 100$ of consumption in five years may be less than the marginal utility generated by an additional $\$ 100$ of consumption now". The same argument is elaborated on in Noor (2009) and Ubfal (2012).

Rather than being a result of preferences, reluctance to save may therefore be a result of perceptions of the future. If an optimistic outlook is a way for the poor to improve well-being today, then the low willingness to save may be a by-product of this coping strategy.

Our analysis of optimism shares some of the spirit and some of the building blocks of Basu's (2016) analysis of simultaneous borrowing and saving. The results are quite contrary however. In his model rational hyperbolic discounters use unsecured savings to discipline future self. In our model exponential discounters becomes indisciplined by optimism and engage in excess borrowing.

\section{Positive illusions as a coping strategy}

In the psychological literature several authors have pointed out that illusionary positive view on the future may have a positive effect on well-being. Taylor and Brown (1988 and 1994), for example, question the traditional view that accurate perceptions of the world are essential for mental health. They emphasise how positive illusions may make an individual more robust and productive. Optimism as a coping strategy for the poorest is the particular focus in the paper by Graham and Hoover (2007) with the telling title Optimism and Poverty in Africa: Adaptation

\footnotetext{
${ }^{1}$ Two quite recent examples on studying interventions that may stimulate savings from their low levels are Ashraf, Karlan, and Yin (2006) and Duflo, Kremer, and Robinson (2011).

${ }^{2}$ Several authors have contributed to this line of reasoning. Notable contributions that are particularly relevant for our discussion are Loewenstein \& Prelec (1992) and Laibson (1996) \& Basu (2011, 2014, 2016).
} 
or a Means to Survival?. They write in the abstract: "We find unusual levels of optimism among the poorest and most insecure respondents there, in contrast to the other regions, where optimism is positively correlated with wealth and education. This suggests that optimism may play a positive role in the survival of the very poor in such adverse circumstances".

Two other recent studies also tell us that people in developing countries are more optimistic than people in richer economies. The Pew Research Global Attitudes Project Survey Report states that "[e]ven though many in Africa continue to face serious financial adversity, their economic outlook is more positive than many others around the world, and they are hopeful about their children's future". In general, Africans, Asians and Latin Americans express more positive views about economic conditions and are more optimistic for the next generation than people from Europe and the Middle East ${ }^{3}$. The Afrobarometer study is undertaken biannually in several African countries. A policy brief reports that 57 percent of Africans expect the national economy to be better in a years' time, despite the fact that 53 percent rate the current economic situation as "fairly" or "very" bad, and less than a third (31 percent) felt there had been an improvement from the year before (Hofmeyr 2013).

\section{Preview of the empirics}

In our empirical part we use survey data from the National Income Dynamics Study (NIDS) in South Africa. For South Africa we also find high degrees of optimism. In the survey people are asked to "[..] imagine a six step ladder where the poorest people in South Africa stand on the bottom (the first step) and the richest people in South Africa stand on the highest step (the sixth step)." They are then asked on which step they perceive themselves to belong to today, and on which step they expect to be two and five years hence. For each year, the sample consists of around 15,000 South Africans aged 15 or older.

Figure 1 shows the distribution of subjective ranking today, and expected ranking in two and five years respectively. The survey was conducted in 2008, 2010 and 2012 and we are able to compare actual outcome to that expected two or five years before. Each row depicts the survey year, each column depicts current year and the two expected futures. There is some variation between the years, but the pattern is the same; we see a clear tendency of optimism that increases with time horizon. In each observation year the distributions shift towards the right when comparing the current situation to expectations about the future. Comparing current subjective ranking in 2010, with what was the expectation held in 2008 for the two year horizon (that is for 2010 in red), we see that people in 2008 expected to shift much further to the right than what they actually ended up experiencing. The same pattern can be seen when comparing current subjective ranking in 2012 with expectations held in 2010, for the two year horizon (that is for 2012 in red). And finally, comparing current subjective ranking in 2012, with expectations held in 2008 for the five year horizon (that is for 2013 in blue) ${ }^{4}$, we see that the optimistic bias is even more

\footnotetext{
${ }^{3}$ URL:http://www.pewglobal.org/2013/11/08/despite-challenges-africans-are-optimisticabout-the-future/, accessed 11 December 2014.

${ }^{4}$ Note for some this would be expectations for 2013 but we only have data for 2012 .
} 
enhanced. In each period people expect to advance with time, yet when that period becomes "today", they still see themselves among the poorer parts of society.

Figure 1: Distribution of subjective ranking today, in 2 years in 5 years

Today
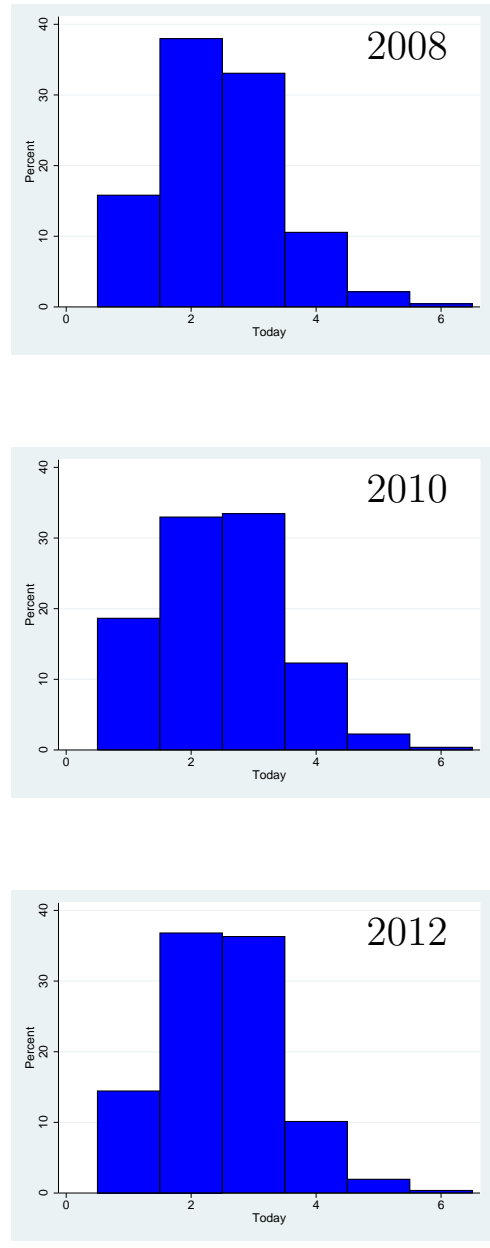

In 2 years
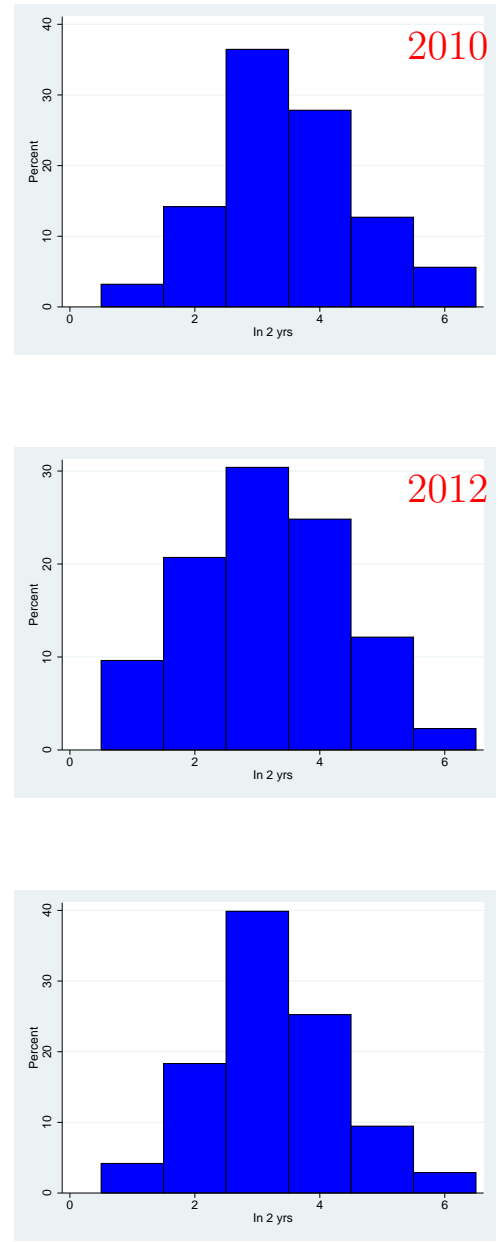

In 5 years
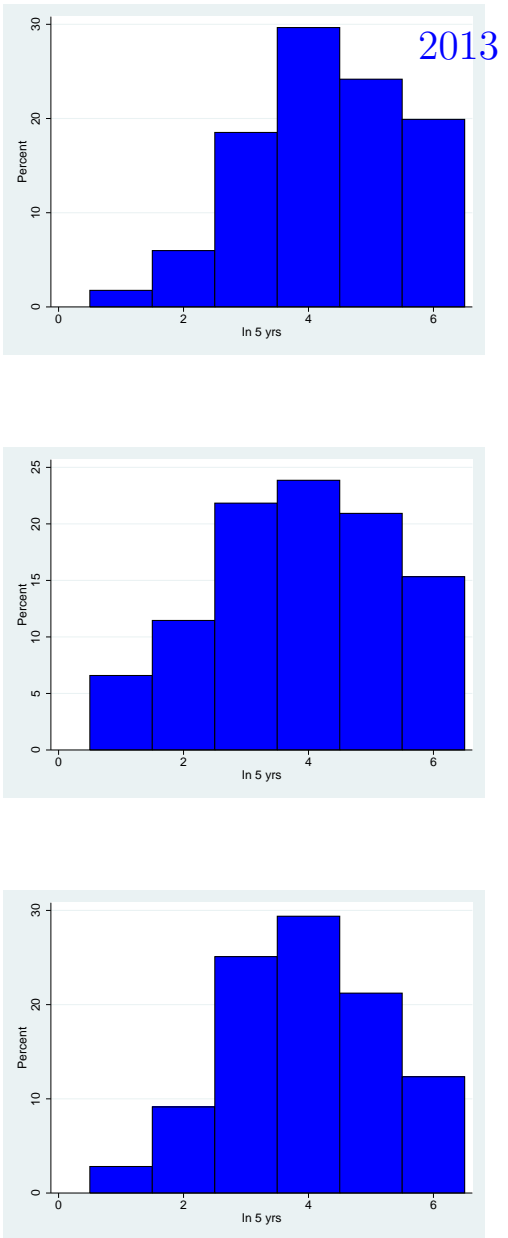

In Figure 2 we give a complementary view and focus on the poorest segments. We have limited the sample to individuals who rank themselves on step one or two on the ladder, i.e. amongst the bottom third. Here we show the distribution of subjective ranking vs. the two year horizon in the left panel, and the distribution of subjective ranking today vs. the five year horizon in the right panel. We see that even amongst this group of the self-perceived poorest South Africans, there is a non-negligible fraction of individuals who expect to be on top of the ladder in five years' time.

\section{Positive illusions and its adverse effects.}

So positive illusions are prevalent in poor countries. Is that a good thing or a bad thing? Approaching this issue from an expected utility framework, and in line with 
Figure 2: Poors' rating today vs. expectation 2 years and 5 years hence.
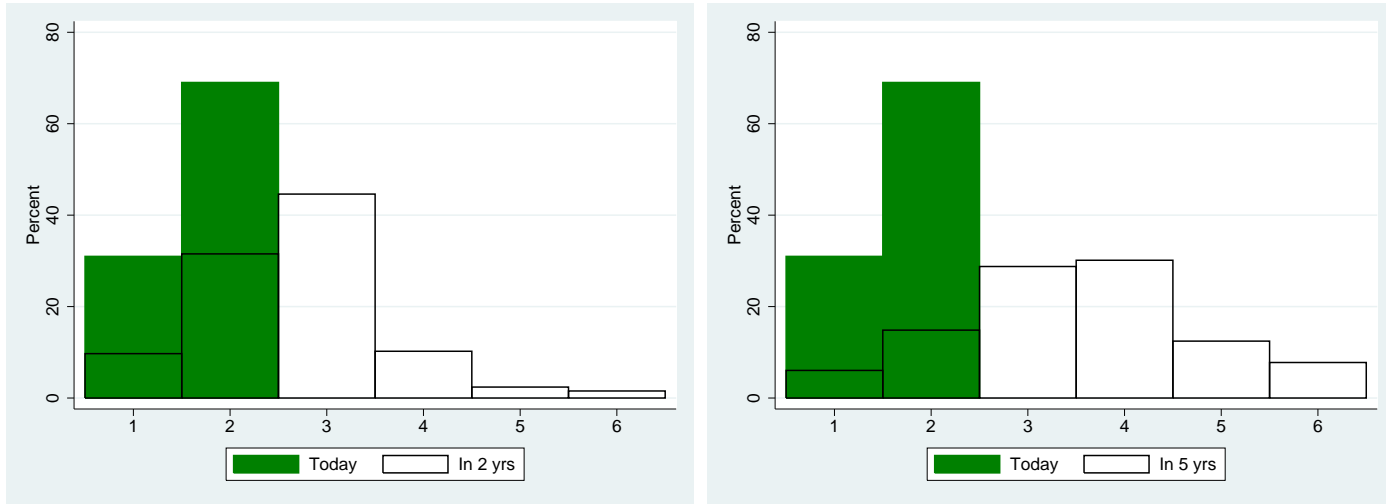

Taylor \& Brown, it should be no surprise that well-being may be positively affected if an individual heightens his expectations for the future. All else equal it should not matter much for the immediate appreciation of positive expectations whether the expectations are based on illusions or on reliable information.

Of course, when the reality about the future eventually is realised the illusions cannot be sustained. However, that cannot reverse the anticipation of a positive future that already has had its positive effect. Hence, positive illusions may boost well-being simply by increasing the subjective (illusory) expected utility. Moreover, Taylor and Armor followed up the theme in 1996 in a extensive review article, where summarising a large literature, they wrote: "The fact that beliefs in one's own abilities, a sense of personal control, and optimism about the future are associated with the use of active coping strategies is important because it indicates that positive illusions are not wish-fulfilling beliefs that numb people into inaction, but rather constitute positive assessments that lead to favorable appraisals of one's ability to take active measures in response to stress". (p. 883). Hence, they view the positive illusion, in contrast to other psychological coping strategies, as something that does not pacify the individual.

So are positive illusions unambiguous a good thing? Not necessarily. There are degrees of illusion, and some limited research indicates that some groups are more unrealistically optimistic than others. If the positive illusion goes as far as directly biasing the individual's behaviour, he might take actions he later regrets. These could be actions related to risk taking for individuals who think they have particularly good fortune, as is true for most of us (see Weinstein 1980). De Meza \& Southey (1996) discuss how optimism among entrepreneurs create something they call "borrower's curse". Arabsheibani et al (2000) study empirically the degree of optimism among entrepreneurs and compare self-employed with employed. They find that entrepreneurs are more optimistic than employed individuals, and that they experience worse realisations. This is consistent with theories that many entrepreneurs are motivated by particularly unrealistic optimism rather than by a particular talent. 
A related adverse effects is the one we explore in this paper. Individuals, who wrongly assume that their prospective income growth is going to be high, will be tempted to borrow. In particular we focus on problems that arises as a result of informal money lenders. But we also consider problems that may arise if individuals that were previously excluded from the credit market get access to cheap credit.

In many developing countries, formal credit markets are either non-existent, or they exclude the poor majority. The NIDS survey reveals that only around 27 percent of the South African population below the poverty line of R620 5 per month had a bank account in 2012. In contrast, 84 percent of Whites $\operatorname{did}^{6}$. One result of this can be that the poor only get access to expensive credit. Collins et al (2009) found that most moneylender rates in South Africa run at about 30 percent per month. Although commercial banks aim to maximise their profits, they usually have some interest in helping loan takers repay their loans. This is not necessarily the case for other suppliers of credit, whose main interest is to maximise interest rate cash flow rather than stimulating down payments.

Over-indebtedness is a major theme in developing countries, and South Africa is a case in point. According to the South African Reserve Bank (2014), the debt-todisposable income ratio increased from 56.5 percent at the time of the first democratic election, peaked at close to 90 percent in 2007, and has since fallen moderately to reach 78.3 percent in December 2014. The Reserve Bank (2013) notes a structural shift in credit extension, with an increase in non-mortgage debt in the household sector, and expansion in unsecured lending. A national newspaper reports that "[loan] sharks and micro-finance offices have mushroomed in South Africa's innercity centres" 7 .

The contributions of our article are three. First, we make the connection between optimism as a coping strategy for the poor and reluctance to save. We thereby provide one possible explanation for the low savings that have been observed in poor countries. Second, we show how optimism generates a willingness to borrow that is increasing in indebtedness. The reason is that as consumption possibilities are driven down by debt service, expectations about income growth will be even more salient and the measured discount rate will go up. We thus show how an optimistic individual may lure himself into a debt trap. Third, we document empirically that optimism indeed is prevalent among South Africa's poor and we document a positive relationship between optimism and the willingness to take up debt.

\footnotetext{
${ }^{5}$ This "upper bound" poverty line is defined as the "the level of relative deprivation below which people cannot afford the minimum desired lifestyle", see the report "Poverty trends in South Africa" from Statistics South Africa, 8 April 2014.

${ }^{6}$ We are using the racial categories as defined by the Apartheid government. There were four such categories; Coloureds, Asians (Indians), Africans and Whites.

${ }^{7}$ Daily Maverick, 19 May 2012. URL: http://www.dailymaverick.co.za/article/2012-05-19poverty-how-the-other-half-live/\#.VIRijXbKzIU, accessed on 6 December 2014.
} 


\section{The Argument}

Consider a consumer that maximises consumption over two periods

$$
U=u\left(c_{1}\right)+(1-\rho) u\left(c_{2}\right)
$$

where $c_{t}$ is the consumption in period $t$ and where $\rho$ is the discount rate. $U$ is maximised given an intertemporal budget constraint

$$
(1+r) c_{1}+c_{2} \leq(1+r) y_{1}+y_{2}
$$

where $r$ is the interest rate between period 1 and 2 and $y_{t}$ is the income in period $t$. When the agent is free to borrow and save at rate $r$, the solution is found by by maximising the Lagrangean

$$
\mathcal{L}=u\left(c_{1}\right)+(1-\rho) u\left(c_{2}\right)-\lambda_{1}\left((1+r) c_{1}+c_{2}-(1+r) y_{1}-y_{2}\right)
$$

The first order condition can be written

$$
u^{\prime}\left(c_{1}\right)=(1-\rho)(1+r) u^{\prime}\left(c_{2}\right)
$$

As the marginal utility of consumption decreases with consumption, this condition states that consumption in period 1 will be relatively higher the lower the rate of return on savings ( $r$ down) and the lower the weight put on the future ( $\rho$ up). In optimum the multiplier $\lambda_{1}$ captures the marginal utility of an increase in period 2 income

$$
\lambda_{1}=(1-\rho) u^{\prime}\left(c_{2}\right)=u^{\prime}\left(c_{1}\right) /(1+r)
$$

Now, an individual who gets the choice between a small increase in consumption in period 1 by a small number $a_{1}$ and an increase in consumption in period 2 by $a_{2}$ would be indifferent between the two if

$$
u^{\prime}\left(c_{1}\right) a_{1}=(1-\rho) u^{\prime}\left(c_{2}\right) a_{2}
$$

Combined with (4) we see that the condition for being indifferent is that

$$
\begin{array}{r}
1+r=1+\tilde{\theta} \\
\text { where } \tilde{\theta} \equiv \frac{a_{2}-a_{1}}{a_{1}}
\end{array}
$$

This implies that the growth rate of $a, \tilde{\theta}$, has to be equal to $r$ in order for the individual to be indifferent between the two alternative additions to consumption in the two periods. A consumer with frictionless access to a credit market would be indifferent between the alternatives of an addition to consumption in period 1 and 2 only if the addition in period 2 was $1+r$ times the addition in period 1 . The reason is, of course, that optimality assures that the marginal unit of consumption was distributed so that the interest return is exactly balanced against the differences in marginal utility. Therefore if we use interviews or experiments to elicit $\tilde{\theta}$ for a 
subject who is free to save or borrow at rate $r$, for example by asking "what would you prefer, $a_{1}$ today or $a_{2}$ in one year?", we would elicit information about the credit market terms the subject is facing and not learn anything about time preferences of the subject.

Without access to the credit market the consumers' problem would be different. Now, consumption in each period has to be equal to income in the same period $\left(c_{1}=y_{1}\right.$ and $\left.c_{2}=y_{2}\right)$. There is thus no scope for inter-temporal optimisation. Setting up the Lagrangean is nevertheless valuable as it allows for an evaluation of the utility consequences associated with not having access to the credit market. The credit market constraint $\left(c_{1}=y_{1}\right)$ can be included in the Langrangean with multiplier $\lambda_{2}$.

$$
\mathcal{L}=u\left(c_{1}\right)+\rho u\left(c_{2}\right)-\lambda_{1}\left((1+r) c_{1}+c_{2}-(1+r) y_{1}-y_{2}\right)-\lambda_{2}\left(c_{1}-y_{1}\right)
$$

Now the first order conditions, rather than determining consumption, determines the cost of credit market exclusion $\lambda_{2}$.

$$
\lambda_{2}=u^{\prime}\left(c_{1}\right)-(1-\rho)(1+r) u^{\prime}\left(c_{2}\right)
$$

By comparing with (4) we see that $\lambda_{2}$ is a measure of the utility consequences of departing from inter-temporal optimality. A direct use of the (10) is to measure the gains from opening up access to the credit market with interest $r$. A measure of the severity of the constraint is found by calculating the hypothetical interest rate $r^{*}$ that would have been the consistent with the individual not wanting to adjust the exogenously given consumption pattern. By setting $\lambda_{2}=0$ we get

$$
u^{\prime}\left(c_{1}\right)=(1-\rho)\left(1+r^{*}\right) u^{\prime}\left(c_{2}\right)
$$

Now, if this individual gets the choice between an increase in consumption in period 1 by a small number $a_{1}$ and an increase in consumption in period 2 by $a_{2}$, the individual would be indifferent between the two if

$$
\frac{a_{2}-a_{1}}{a_{1}}=r^{*}=\frac{1}{(1-\rho)} \frac{u^{\prime}\left(c_{1}\right)}{u^{\prime}\left(c_{2}\right)}-1
$$

The $r^{*}$, defined in (11) is therefore a measure of the willingness to pay for shifting consumption forward in time. If $r^{*}$ is high it means that the individual would prefer a small addition to consumption in period 1 to a larger addition to consumption in period 2. The individual would be indifferent only if he was faced with the prospect of $a_{2}$ being larger by the rate $r^{*}$.

The expression can be simplified further by inserting a first order approximation to $u^{\prime}\left(c_{2}\right)$,

$$
u^{\prime}\left(c_{2}\right)=u^{\prime}\left(c_{1}\right)\left(1+\frac{u^{\prime \prime}\left(c_{1}\right) c_{1}}{u^{\prime}\left(c_{1}\right)} \frac{c_{2}-c_{1}}{c_{1}}\right) .
$$


Inserting in (12) yields

$$
r^{*}=\frac{1}{1-\rho} \frac{1}{1+\frac{u^{\prime \prime}\left(c_{1}\right) c_{1}}{u^{\prime}\left(c_{1}\right)} \frac{c_{2}-c_{1}}{c_{1}}}-1
$$

Then, when considering the continuous time approximation we can simplify further by writing

$$
\begin{aligned}
r^{*} & =\rho+\frac{\gamma}{\sigma} \\
\text { where } \gamma & \equiv \frac{c_{2}-c_{1}}{c_{1}}, \quad \sigma \equiv-\frac{u^{\prime}\left(c_{1}\right)}{u^{\prime \prime}\left(c_{1}\right) c_{1}}>0
\end{aligned}
$$

where $\gamma$ is the exogenously given growth rate of consumption and where $\sigma$ is the intertemporal elasticity of substitution. It should be no surprise that equation (14) reflects exactly the same trade offs as the standard continuous time Euler equation. The interpretation of equation (14), however, is quite different from the standard interpretation. Rather than being an optimality condition for consumption given the return on savings (14) shows the preferences for present consumption given an exogeneous consumption path (the baseline path). The $r^{*}$ is the willingness to pay for shifting consumption forward in time. Based on (14) we can formulate the following proposition

Proposition 1. The willingness to pay for shifting consumption forward in time $r^{*}$ is high if the discount rate $\rho$ is high or if the baseline consumption growth rate is high. The willingness to pay, i.e. $r^{*}$, will be particularly high if the elasticity of substitution is low.

The consequence of the proposition is that there will be a direct relationship between the willingness to pay for current consumption $r^{*}$ and time preference $\rho .^{8}$ Therefore if we use interviews or experiments to elicit $r^{*}$, we would get some information about $\rho$. In order to go from a measure on $r^{*}$ to a measure of $\rho$, however, also information on $\gamma$ and $\sigma$ would be needed. Only in the case of no baseline consumption growth $(\gamma=0)$ would $r^{*}$ be a direct measure of $\rho$. If consumption is expected to increase $\left(c_{2}>c_{1}\right.$ and thus $\left.\gamma>0\right), r^{*}$ would be larger than $\rho$. If this is not corrected for, interpreting $r^{*}$ as a direct measure of $\rho$ would lead to an upward bias. If, however, the individual was expecting a consumption decline, i.e. $\gamma<0$, using $r^{*}$ would lead to a downward bias.

The bias could indeed be large. If, for example, the true rate of time preferences is $\rho=10 \%$ and if a consumption growth of 45 percent is expected $(\gamma=45 \%)$ and if the elasticity of intertemporal substitution is $\sigma=0.5$, then we would get a measured willingness to pay for present consumption of $r^{*}=100 \%$. Using $r^{*}$ as a direct proxy for $\rho$ would therefore overestimate the true $\rho$ by a factor of ten. ${ }^{9}$

\footnotetext{
${ }^{8}$ This is in contrast to the perfect credit market case where the willingness to pay for current consumption is exactly determined by the credit market condition. When credit markets are functioning perfectly the willingness to pay does not convey any information about preferences.

${ }^{9}$ This bias becomes larger the smaller the elasticity of substitution. Masao, Ostry and Reinhart (1996) have estimated the intertemporal elasticity of substitution for low and middle income coun-
} 
Optimism about future income growth could therefore easily account for very high degrees of impatience. Faced with such high measures of the discount rate it could be tempting, as has been done in many recent studies, to interpret the impatience as a result of hyperbolic discounting. In the following section we derive the willingness to defer consumption that would follow from hyperbolic discounting. We then derive the baseline consumption growth that in the above standard model that would generate a willingness to defer consumption indistinguishable from that following from hyperbolic discounting.

\section{Consumption bounce-back versus hyperbolic dis- counting}

Departures from the standard exponential discounting often takes the form of hyperbolic discounting. Loewenstein and Prelec (1992) weights events $\tau$ periods away with

$$
D(\tau)=(\alpha \tau+1)^{-\theta / \alpha}
$$

with all parameters positive. As $\alpha$ approaches zero the expression approaches exponential discounting.

$$
\lim _{\alpha \rightarrow 0} D(\tau)=e^{-\theta t}
$$

The discounting function (15) exhibits decreasing rate of time preferences. The willingness to delay consumption at time $\tau, \tilde{r}$ is given by the elasticity

$$
\tilde{r}(\tau)=-\frac{D^{\prime}(\tau)}{D(\tau)}=\frac{\theta}{\alpha \tau+1}
$$

Now we may compare two individuals; individual A with hyperbolic discounting and stable baseline consumption and individual B with standard discounting and growing baseline consumption. What pattern of consumption growth would be required for $\mathrm{B}$ to report a willingness to pay for shifting consumption forward in time indistinguishable from that reported by A?

In order to derive this hypothetical consumption growth we start from the condition that the willingness reported by A, $\tilde{r}$ from (17), is equal to the willingness reported by $\mathrm{B}, r^{*}$ from (14), for all $\tau$. The condition is

$$
\frac{\theta}{\alpha \tau+1}=\rho+\frac{\gamma(\tau)}{\sigma}
$$

Further, when inserting for the consumption growth in continuous time, $\gamma(\tau)=$

tries. Not surprisingly, they find that the closer the income is to the subsistence level, the lower is the elasticity of substitution. For the poor countries as a group, the average is a $\sigma$ of about one third. In that case using $r^{*}$ as an estimate for $\rho$ would miss the true value by a factor of 16 . 
$c^{\prime}(\tau) / c(\tau)$, we get

$$
\frac{c^{\prime}(\tau)}{c(\tau)}=\sigma\left(\frac{\theta}{\alpha \tau+1}-\rho\right)
$$

Hence, if individual B expects consumption growth to be given by (19) then subject $\mathrm{A}$ and $\mathrm{B}$ will report the exact same willingness to transfer consumption between any two points in time. This differential equation may be solved yielding

$$
c(\tau)=c_{0} e^{-\sigma \rho \tau}(\alpha \tau+1)^{\frac{\sigma \theta}{\alpha}}
$$

where $c_{0}$ is the consumption level at time zero. Figure 1 illustrates the relationship between the willingness to defer consumption $\tilde{r}$ and the consumption growth of $\mathrm{B}$. If both $\mathrm{A}$ and $\mathrm{B}$ had the same constant baseline consumption then $\mathrm{A}$ would report $\tilde{r}$ as the willingness to defer while B would report $\rho$. When B has a consumption growth as in the right panel and as given by (20), however, B would report a $r^{*}$ exactly equal to the $\tilde{r}$ reported by A. Because of the expected consumption growth, $\gamma$, B's willingness to defer is lifted up by the amount $\gamma \sigma$.

Figure 3: Consumption growth and the willingness to defer consumption
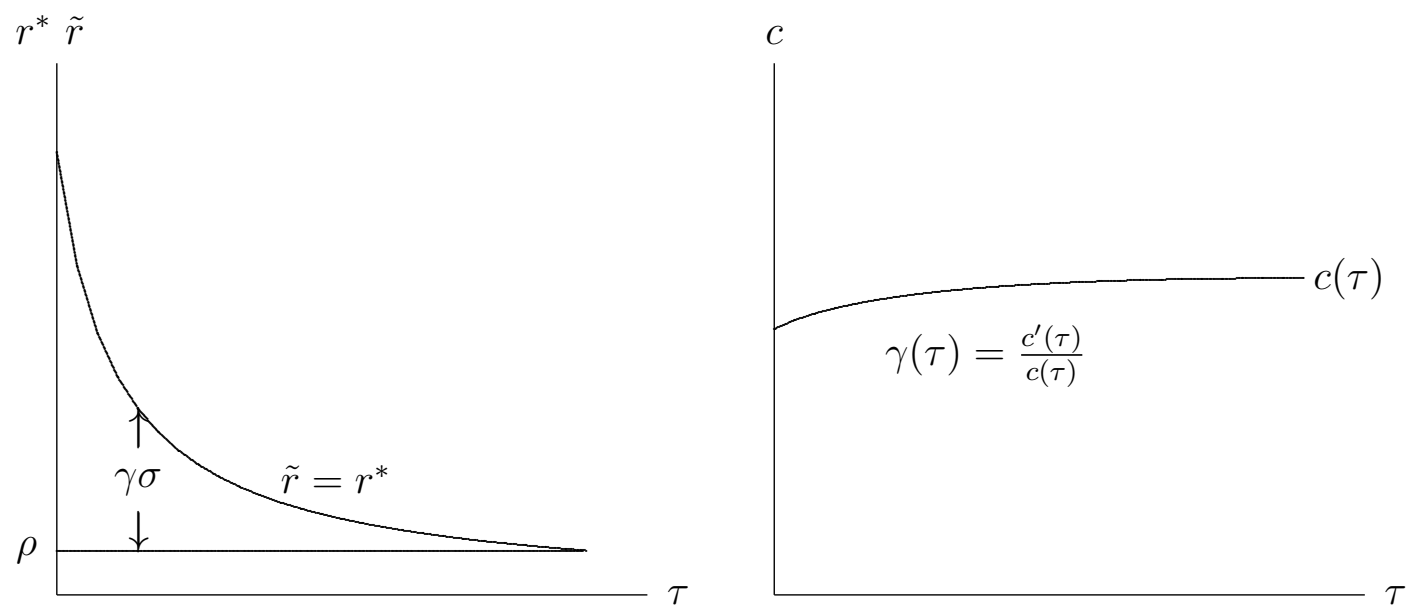

The figure shows how consumption growth in the early phase combined with a relatively small elasticity of substitution causes a subject to report a very high $r^{*}$.

The above derivation shows that, when eliciting discount factors, preferences that appear to strongly reflect hyperbolic utility may in fact be a result of prospects about modest income growth. It is not possible to distinguish the reported willingness to shift consumption forward or backward in time for individual A versus individual B.

In spite of the apparent similarity there are also differences between A and B that could prove substantive for credit market behaviour. For credit policy for example it would be critical to have the correct understanding of the factors underlying a low willingness to save. Is it a result of intrinsic impatience, as with hyperbolic discounting, or is it a result of optimism. And if it is a result of optimism, is the optimism illusionary or well founded? As an illustration of possible adverse effects 
we will derive consequences of introducing access to credit to a person like individual B. A person with constant optimism and never fading outlook that today is the first day of a great recovery.

\section{Illusionary optimism and the willingness to pay for credit}

In this illustration we explore how a borrower like $\mathrm{B}$, with illusionary optimistic expectations about the future, may end up in a debt trap. Based on illusionary expectations and an unchanging optimism, B's willingness to defer consumption will be low and the willingness to pay for credit will be high. But, given that the bright future never materialises and given that B does not lose his optimism he will, as long as the interest rate is acceptable, continue to borrow.

To simplify we abstract from the possibility of defaulting on the debt. Instead we assume that there is a limit to how much B may lend and that the limit is given by the debt level giving an interest amount equal to total income. We assume that, when the limit is reached, B will have to service the interest on the outstanding debt using current income. We denote by $\beta$ the debt service in proportion to income in a current period $t_{0}$ and we denote income in the same period $y_{0}$. We can derive the illusionary expected consumption path of individual B under the assumption of no further borrowing. Letting $t=t_{0}+\tau$ and modifying (20) by subtracting $\beta y_{0}$, the expected consumption path will be

$$
c^{*}(\tau)=y_{0} e^{-\sigma \rho \tau}(\alpha \tau+1)^{\frac{\sigma \theta}{\alpha}}-\beta y_{0}
$$

Therefore at $\tau=0$ the growth rate of $c^{*}$, the illusionary expected consumption growth of B, without further borrowing, will be

$$
\gamma^{*}=\sigma \frac{\theta-\rho}{1-\beta}
$$

The equation shows that there is an upward sloping relationship between debt service and the expected consumption growth. The reason is that for a expected fixed income path relative growth is larger when a constant number is subtracted.

Combining with (17) it follows that the current willingness to pay for credit at any time $t_{0}(\tau=0)$ will be given by

$$
r^{d}=\frac{\theta-\rho \beta}{1-\beta}
$$

The marginal willingness to pay for an additional unit of credit $r^{d}$ is therefore an increasing function of a given debt service fraction $\beta$. An illustration of the relationship between consumption path and B's marginal willingness to pay for additional credit is given in Figure 4. The right panel shows two consumption growth paths; one without and one with debt service. The left panel shows the corresponding willingness to pay for credit. The result is generalised in the following 
Figure 4: Debt service and marginal willingness to pay for credit
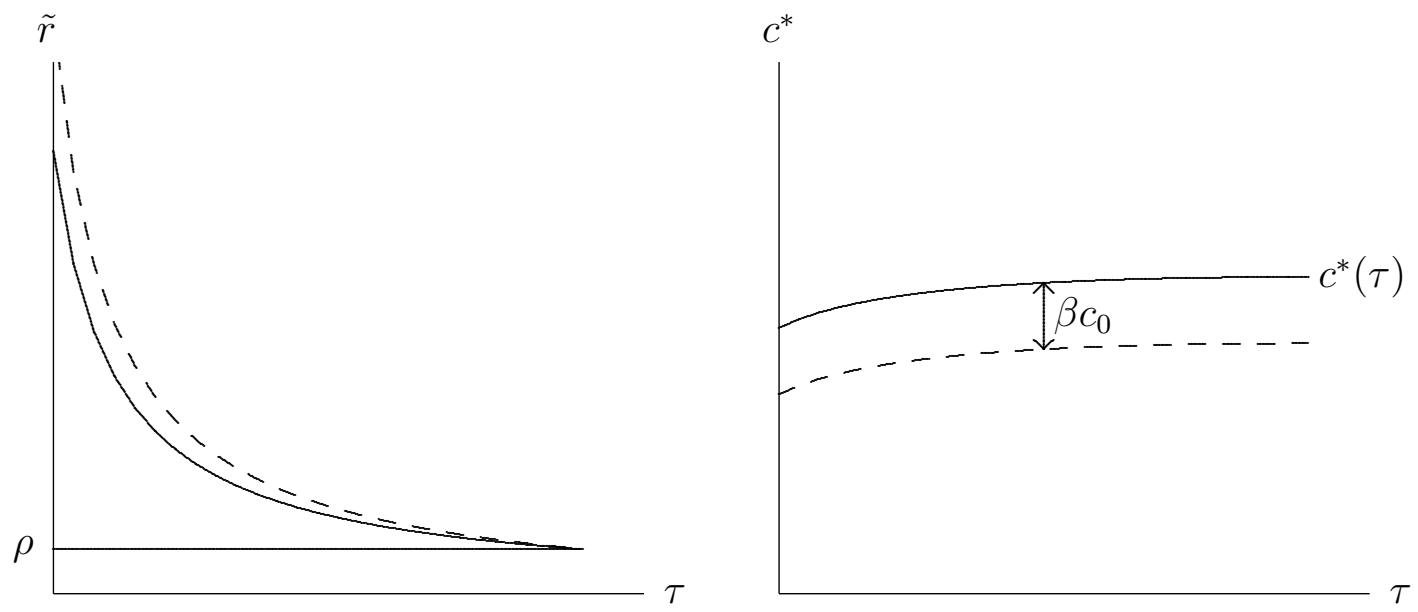

proposition.

Proposition 2. With undisrupted optimism the marginal willingness to pay for credit will be increasing in the debt service. When the discount factor is small the relationship between willingness to pay and debt service is approximately an hyperbola.

Proof. The first part follows immediately from (23) while the last part follows when setting $\rho$ to zero.

The implication of the proposition can be quite dramatic. As long as the optimistic individual has a marginal willingness to pay for credit that exceeds the price of credit he will accumulate additional debt. The fact that the willingness to pay for credit increases in the indebtedness may therefore result in a debt trap. In fact, the proposition says that the willingness to pay grows beyond bounds as the debt service approaches unity. Hence, unless the amount of credit is restricted an optimistic individual may end up completely indebted with a debt service ratio of $\beta=1$.

Figure 5: Upward sloping demand for credit

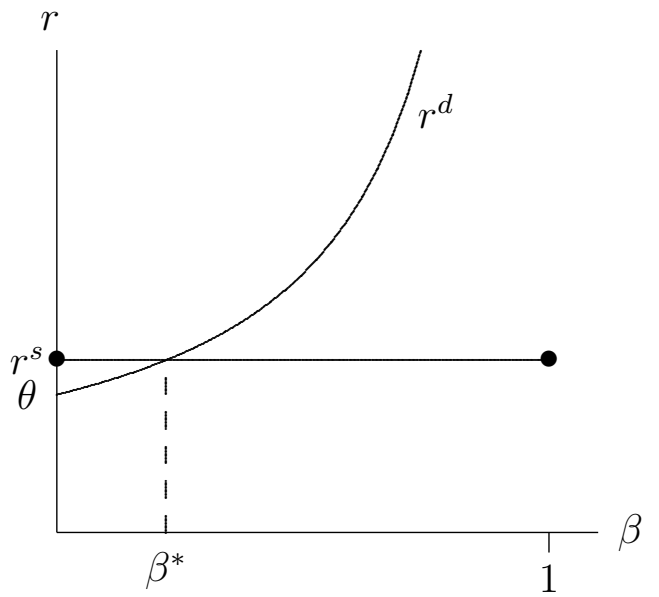


In Figure 5 we have drawn one example of the demand schedule. When $\beta=$ 0 , then the willingness to pay for credit is $\theta$. Then, as $\beta$ approaches unity the willingness to pay grows beyond bounds. Considering the case where the supply of credit is elastic for a fixed high interest rate $r^{s}>\theta$; an optimistic individual starting out without debt would never be willing to pay the price of borrowing. He would remain in a long run equilibrium without debt where $\beta=0$, captured by the bullet to the left. If the debt service level goes beyond $\beta^{*}$, however, the willingness to pay for an additional loan will be larger than $r^{s}$ and the individual will want to accumulate more debt and will eventually end up with maximum debt service, captured by the bullet to the right. Therefore the level $\beta^{*}$ is a critical tipping point that determines whether $\mathrm{B}$ ends up in a debt trap or not. The tipping point for positive $\beta$ is a result of $r^{s}$ being larger than $\theta$. If $r^{s}$ was lower than $\theta$ only the maximum debt service equilibrium would remain.

The left panel of Figure 6 illustrates a more complex situation. The level $r^{s}$ can here be interpreted as the interest rate in the formal credit market. This interest rate is only available for borrowers with less than $\beta^{m l}$ debt service. Borrowers who want to borrow beyond that level will have to approach a money lender and pay the premium interest rate $r^{m l}$. Paying such a high interest rate is not a tempting proposition for an individual with interest service $\beta^{m l}$. Therefore $E_{1}$ will be a low equilibrium. But also here there is a tipping point. Interest service beyond this level induces the individual to expect a consumption growth sufficient for the willingness to pay for credit to exceed $r^{m l}$ and there is thus also a high debt equilibrium in this case. Given our assumption, about the borrower actually servicing the interest, this equilibrium is attractive from the money-lenders point of view. The money-lender may actually be tempted to lure the borrower to move beyond the tipping point.

Figure 6: Money lenders and slippery slope
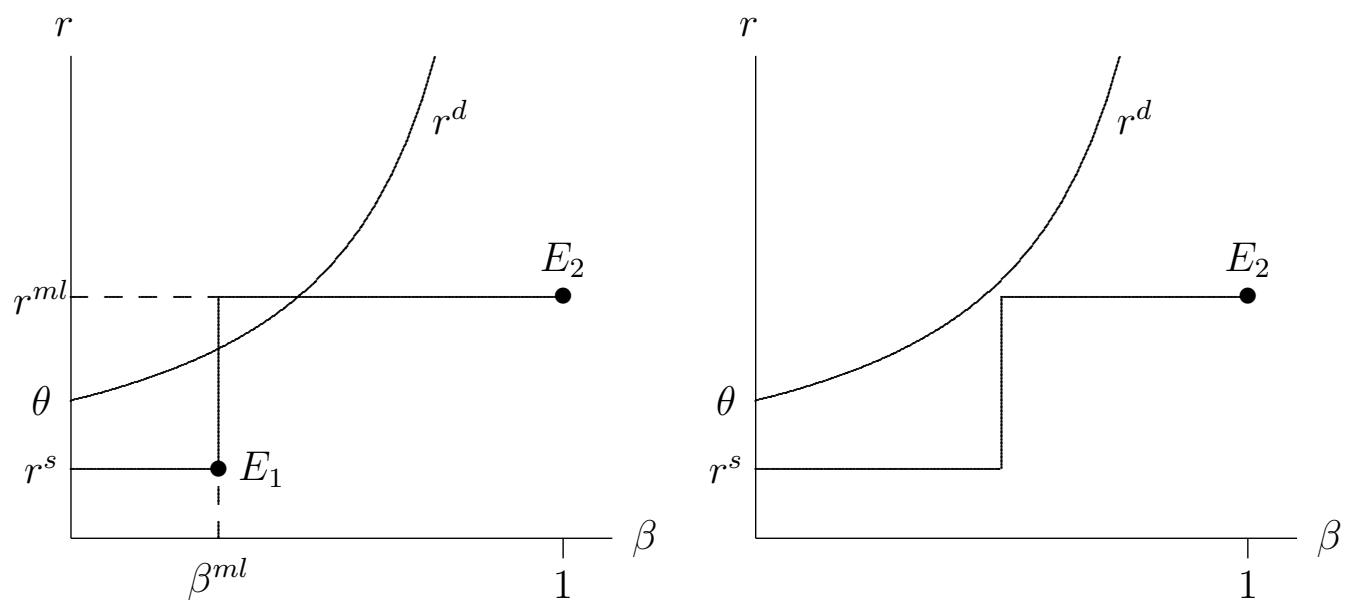

A related situation is illustrated in the right panel. This situation arises if the formal credit, perhaps due to credit policy, moves the right. Then the tipping point goes away and $E_{2}$ would remain as the only equilibrium. The implication being that generous and moderately priced credit would tempt the optimistic borrower to accumulate so much debt that when the formal source is exhausted, the money 
lender appears as an attractive source for further funds. The terms of the money lender would only appear attractive conditioned on the debt already accumulated. In this case the initial cheap credit is exactly what causes the individual to end up totally indebted with expensive debt to the money lender. If the money lender had been the only source of financing the individual would never have started on the slippery slope towards complete indebtedness. This gives a stark example of a case where cheap credit may have adverse long run consequences.

Such consequences are off course only relevant if optimism is a prevalent phenomenon in poor countries and in the last part we explore empirically whether such concerns have any relevance given the expressed optimism of people.

\section{Empirical analysis}

The previous sections have shown how illusionary optimism increases the willingness to borrow. Further we saw how this may lead the individual into a debt trap. We are not able to test all the details of the argument, but we can check the validity of parts of the argument by investigating first the relationship between optimism (be it illusionary or well founded) and borrowing behaviour, and then the degree of illusionary optimism.

We use the first three waves of the National Income Dynamics Study (NIDS) in South Africa, from 2008, 2010 and 2012. This is the first national panel study in the country, with data at the individual and household levels. The first year around 28,000 individuals from 7,300 households were interviewed.

Most data on debt and financial access in South Africa is available only at the level of the household. In the NIDS survey, however, each adult was asked about these matters. As already shown in the introduction, the data also provides interesting information about perceived economic status and expectations for the future. Posel \& Casale (2011) documents that the data should be interpreted with caution. They find that in NIDS there are large differences between perceived subjective rank and actual rank based on reported income. This introduces some issues of interpretation in our study. However, our main analysis builds on expected mobility in subjective rank is the measure of optimism. That the ranks themselves does not always correspond to the objective reality is unavoidable for the cases that we are particularly concerned with, namely the cases of illusionary optimism.

\section{Do optimists take up debt?}

The second proposition states that optimists take up debt. In other words; the reported high willingness-to-pay for credit seen in other studies, need not be due to high discount rates but rather to an optimistic outlook. We investigate this empirically by running the regression specified in the following model:

$$
\text { Debt }_{i t}=\alpha+\beta_{1} \text { Optimist }_{i}+\beta_{2} \text { Shock }_{i}+\beta_{3} \text { Year }_{t}+\beta_{5} \text { Ind }_{i}+\beta_{5} H H_{i}+\epsilon_{i}
$$

In this specification we pool all three waves into one sample. Debt is a dummy for whether a person has at least one loan. The loan types included in the survey 
are; a bond (house loan), personal bank loan, study loan from a bank, study loan from other credit sources, credit card loan, store card loan, hire purchase loan, loan from a money lender, loan from a "mashonisa", a Sotho word for "loan shark", or a loan from a family member or friend. Having at least one loan is a measure of indebtedness. It shows that, unweighted, almost 19 percent of those who answered has at least one loan, or 17 percent of everyone in the sample $(n=16871)$. Weighted to reflect the South African population, these percentages are 24 and 22 respectively.

The variable of interest, Optimist, is first defined as a person expecting to go up one or more steps in either 2 years' or 5 years' time, on the six-step ladder referred to in the introduction. The variable takes the value one if this the case and the value zero if the individual expects to stay on the same step, or go down at least one step. We later work with stronger definitions of optimism; going up two or more, or three or more steps on the ladder.

Shock is a dummy that takes the value 1 if the household has experienced a negative shock during the last year, and takes the value zero otherwise. Year are year dummies for 2010 and 2012 respectively, with 2008 as the reference category. Ind are individual covariates such as age, age squared, education level, and dummies for whether the individual is female or married. $H H$ includes household characteristics such as household size, whether the household is located in a rural area, and log household income. All regressions are clustered at the household level, using survey weights.

The results are shown in Tables 1 and 2. In Table 1 we examine the relationship between optimism and whether or not the individual has debt. We do this for individuals who rank themselves amongst the bottom third (Panel A) or sixth (Panel $B$ ) on the ladder. The outcome variable changes with column. In the first two columns, an optimist is defined as an individual who expects to move at least one step up the ladder from whatever step he or she currently perceive themselves to belong to. The next two columns define an optimist as someone who expects to move at least two steps up the ladder, and so it continues to the last two columns. In Panel $A$, we see that the effect kicks in when an individual expects at least a three steps increase on the economic ladder. The probability of taking up debt increases with almost four percentage points for this group, and increases to almost seven percentage points for those expecting four or five steps up ${ }^{10}$. This is substantial compared to the overall prevalence of debt of 19 percent, and even more so relative to the debt prevalence for the bottom third of 13 percent.

In columns 1, 3, 5 and 7 we use all the controls specified in the regression equation. In columns $2,4,6$, and 8 , however, we additionally control for whether or not the household has experienced a negative shock during the last year. The reason for including the shock variable is that we want to find out whether or not those who are optimistic have a particular reason for being optimistic. Hence, we want to separate between optimism and negative shocks, as the cause of debt accumulation.

We foresee two alternative consequences of experiencing a negative shock that depend on a person's take on life. The first alternative predicts that a negative shock

\footnotetext{
${ }^{10}$ Although most individuals expect to go up one or two steps, around 5.5 percent of the bottom third sample and 9.7 percent of the bottom sixth sample actually expect to move three steps or more.
} 
(for instance the death of someone the person depends on for financial assistance) will cause the individual to expect a reduction in income, which again may cause the individual to take up debt. The second alternative predicts that, for an optimist, the income reduction resulting from the negative shock will be perceived as an extraordinary event to the extent that he believes that "things can only get better". The optimist therefore takes up debt in the belief that it will be easily managed in the future.

The table reveals a strong direct effect of a shock: All else equal those who experience a negative shock increase their debt uptake of around nine percentage points. Controlling for negative shocks changes the optimist coefficient only marginally. It seems like optimists take up debts whether they experience negative shocks or not; the experience of a negative event does not make them more realistic than had they not experienced a negative event. We are facing the situation outlined in alternative two above.

Panel $B$ shows the result for those who rank themselves at the bottom step of the ladder. We see that the probability of taking up debt increases by six percentage points for someone who expects an increase of three steps or more in 2 years' time, and by close to nine percent for someone who expects to move up at least four steps. Again, controlling for negative shocks only changes the coefficient of interest marginally.

These results indicate a pattern whereby the more optimistic you are - i.e. the more steps you expect to go up in the future - the more your optimism is likely to translate into debt. Also, it indicates that individuals who rank themselves lower down the ladder are somewhat more likely to turn the optimism into debt relative to those who see themselves as relatively better off.

The types of debt included in the above measure can be divided into "formal" and "informal" loans. Examining the effects of optimism on informal debt can be valuable given the analysis above and given that low income groups in South Africa traditionally have not had access to formal credit markets.

Moreover, it is likely to be a lot easier to gain access to informal loans than to formal ones, as requirements tend to be lower and incentives for recollecting the debt are not always there. We define informal debt as a dummy taking the value one if the loan is held with a money lender, a mashonisa (loan shark), or family or friends, and taking the value zero otherwise. The results are presented in Table 2, where Panel $A$ provides the results for those who rank themselves in the bottom third, and Panel $B$ provides the results for those who rank themselves in the bottom sixth. For the former, results increase with the number of steps the indvidual expected to move up, and the estimates are significant from two steps upwards. For the latter, the pattern is the same, although the significant effects only kick in for the most optimistic individuals. Again, the magnitude of the effect of five to seven percentage points is substantial compared to the prevalence of debt of 13 percent for the bottom third.

These results are consistent with the hypothesis in the theory part of this paper. Little or no access to formal credit markets combined with an optimistic outlook lead people to take up potentially expensive loans that can cause debt traps. 


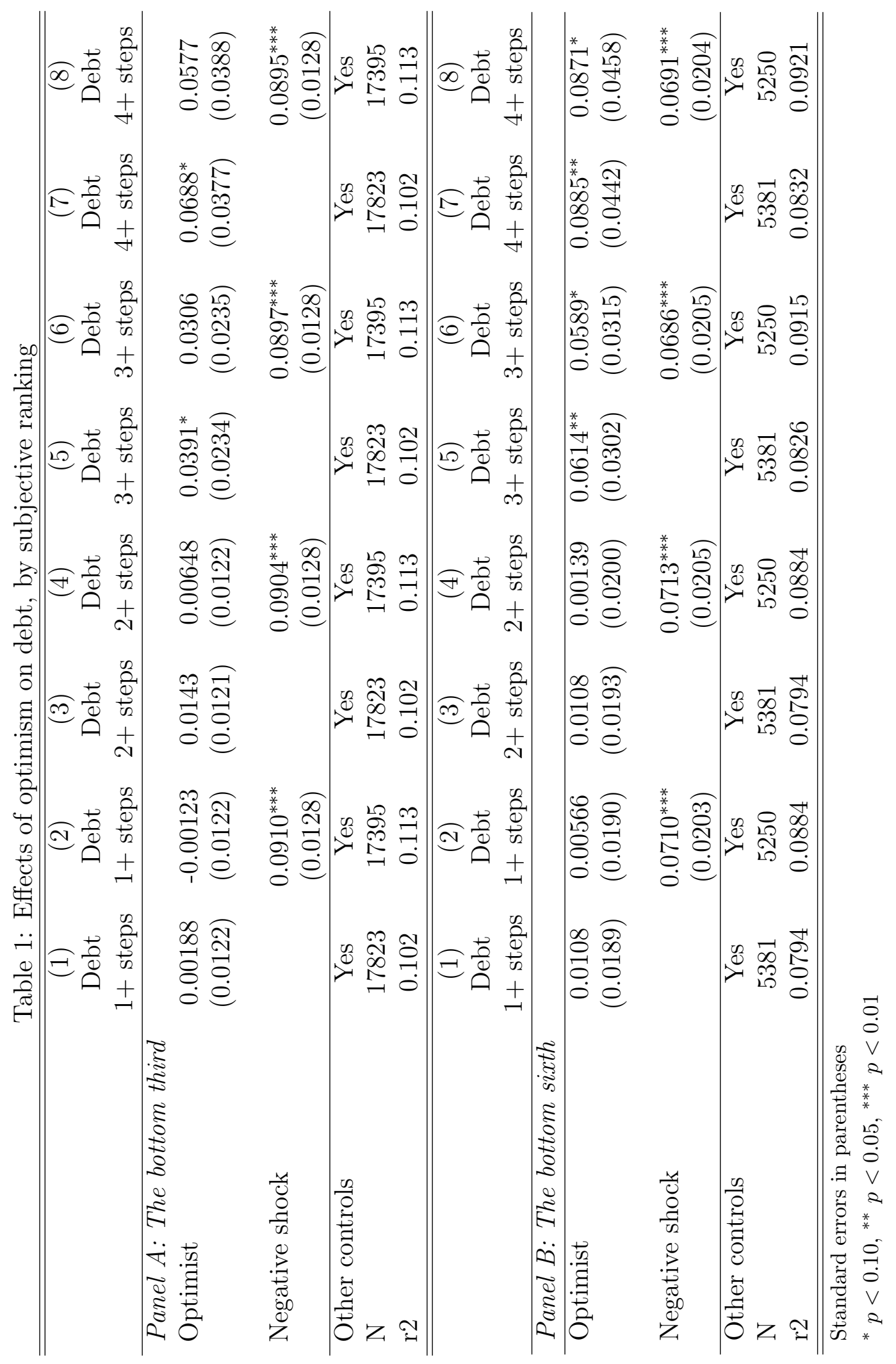




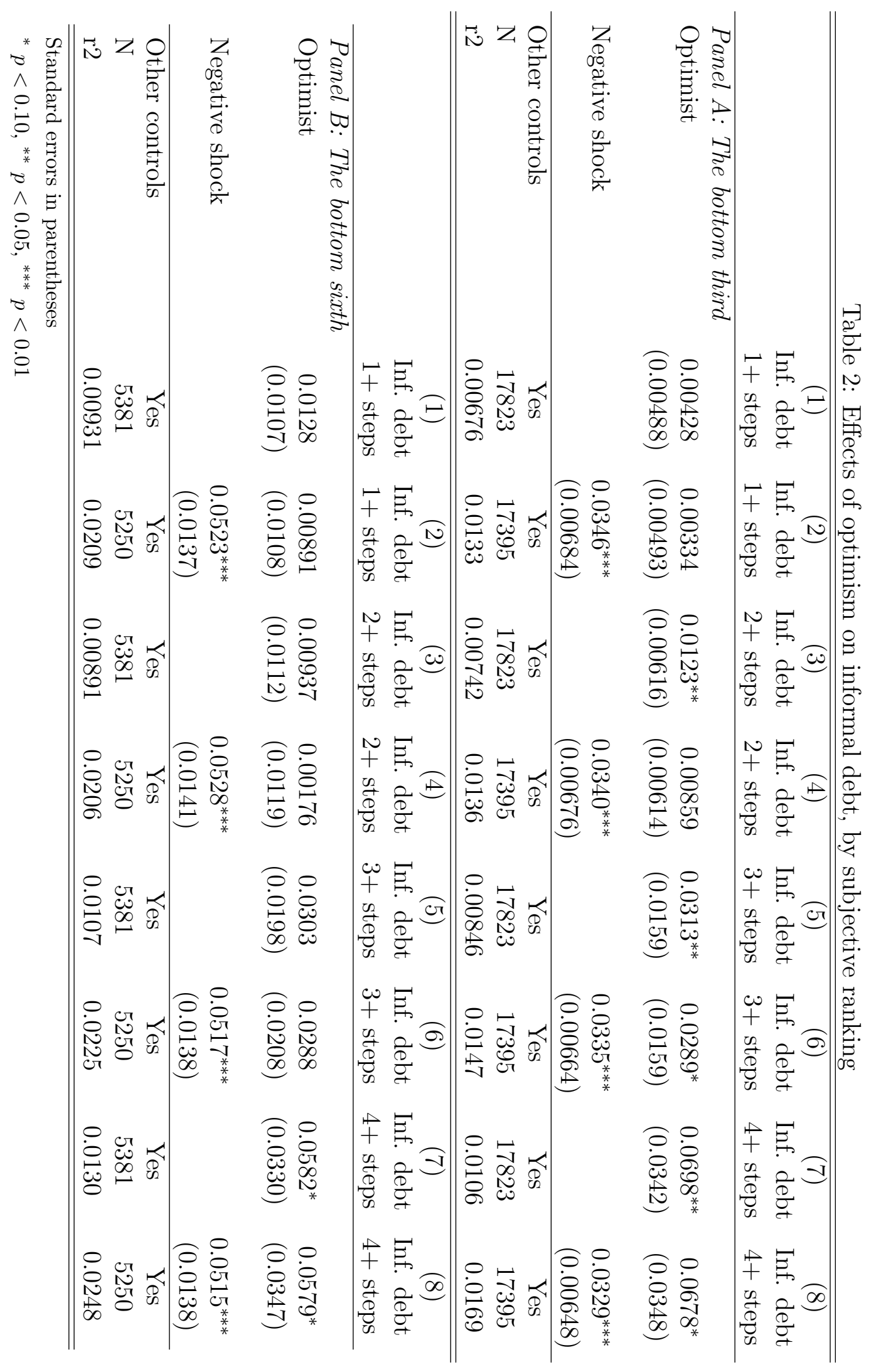




\section{How much illusionary optimism?}

Taking up a lot of debt as a result of optimism is not a problem if the optimism is well-founded. In this case people take up debt, and their income increases sufficiently over time that they are able to keep up with their repayments of principal and interest. If the optimism is illusionary, however, debt accumulation may be highly problematic. As the previous section showed, individuals may take up increasingly larger debts without being able to repay them, and may end up in debt traps. Using the NIDS survey we are actually able to assess the extent of unfounded optimism.

Given the panel structure of the NIDS survey we can compare the optimism one year to the actual outcome two to five years later. The survey divides the economic condition into a six step ladder. To create a measure of unrealistic optimism, we divide the sample of households into sixtiles based on total per capita income. The mean rand value in each sixtile, weighted to reflect the South African population, is R170 per month for sixtile one, R334 for sixtile two, R517 for sixtile three, R803 for sixitle four, R 1398 for sixtile five, and R7697 for the top sixtile.

We then define unrealistic optimism as expecting to step up at least one step from where you perceive yourself to be, but actually - in Rand value - falling back at least one step, i.e. one sixtile, from where you were. We can make this comparison between what people expect in 2008 and 2010 respectively, and what actually happens, as we have income data for up to and including 2012.

Table 3: Realised vs. expected change in income steps

\begin{tabular}{|c|c|c|c|c|}
\hline & $\begin{array}{c}(1) \\
\text { Expect } \\
\text { worse }\end{array}$ & $\begin{array}{c}(2) \\
\text { Expect } \\
\text { same }\end{array}$ & $\begin{array}{c}(3) \\
\text { Expect } \\
\text { better }\end{array}$ & Total \\
\hline Realise worse & 128 & $\begin{array}{c}1745 \\
(27 \%)\end{array}$ & $\begin{array}{c}4162 \\
(29 \%)\end{array}$ & $\begin{array}{l}6036 \\
28 \%\end{array}$ \\
\hline Realise same & 189 & 2894 & 5594 & $\begin{array}{l}8682 \\
41 \%\end{array}$ \\
\hline Realise better & 93 & $\begin{array}{c}1877 \\
(29 \%) \\
\end{array}$ & $\begin{array}{c}4597 \\
(32 \%) \\
\end{array}$ & $\begin{array}{l}6561 \\
31 \%\end{array}$ \\
\hline Total & $\begin{array}{l}410 \\
2 \%\end{array}$ & $\begin{array}{l}6516 \\
31 \%\end{array}$ & $\begin{array}{c}14353 \\
67 \%\end{array}$ & $\begin{array}{l}21279 \\
100 \%\end{array}$ \\
\hline
\end{tabular}

Source: Own calculations from NIDS data, using survey weights

Table 3 shows the level of unrealism in people's expectations. For instance, about $2 / 3$ of adults expected to move up the economic ladder, although only $1 / 3$ of them did. Similarly, less than two percent of adults in the sample expect their financial situation to worsen over the next year. However, 29 percent experienced a drop in per capita income of at least one sixtile.

We see that the general pattern is that of optimism. Moreover, by comparing the optimists in column 3 to the realists in column 2 we see that in both groups about $1 / 3$ experience an improvement while $1 / 3$ experience a deterioration (the column percentages are in parentheses). For both realists and optimists, the median 
as well as the mean are of no change. The only difference is that the outcomes for optimists have slightly larger variability. One natural interpretation of this similarity in averages between realists and optimists is that optimism on average is not well founded. The difference in variability is a combined result of 1) some individuals with a reason for optimism, explaining a few extra experiencing a better outcome and 2) some individuals with reason for pessimism that use illusionary optimism as a coping strategy, explaining a few extra experiencing a worse outcome.

\section{Do individuals learn over time?}

Lastly, we want to examine how optimism develops with age. If optimism goes down as the subjects get older it may indicate that optimism fades as people learn some lessons. If there is sufficient learning, the debt trap we derive will not be a real problem. In Figure 7, we have split the sample for the survey year 2008, by age groups. As in Figure 1, the columns depict current year and expectations 2 and five years into the future. Each row now depicts different age groups. The top row includes individuals aged 15-30 years old, the middle row includes individuals aged 31-45 years old, and the last row includes individuals aged 46-60 years old.

We first note that the distribution of how people see their current situation as remarkably similar across age groups. This gives us a clean basis for comparison. We see a strong degree of optimism at all ages. There is a somewhat less right shift for older people. That people become a little less optimistic with age could be consistent with some degree of learning. The difference is moderate and the optimism among the old is strikingly high given that they all should know quite well what career path the conceivably could follow. Hence, we conclude that optimism is a prevalent phenomenon that does not fade with age. Illusionary optimism may be a satisfying coping strategy but comes with the possibility of a debt trap.

\section{Conclusion}

Why are poor people reluctant to save? In the literature several explanations have been put forward. We have provided an alternative explanation based on positive illusions about future prospects. We have shown how the low willingness to save observed in experiments and surveys that may be interpreted as high discount rates, is equally compatible with an over-optimistic outlook. As discussed in the psychological literature, an illusionary positive view of the future may be a good thing. However, if it leads individuals to accumulate unsustainable levels of debt, positive illusions have a substantial cost. We show how the combination of an optimistic outlook and access to expensive credit can lead poor individuals into a debt trap. Using survey data from South Africa, we confirm that people are indeed overly optimistic, and also that optimism is positively and significantly related to debt uptake. In the article we focus on poor countries. We believe that the mechanisms we explore may also be relevant for richer countries. For example as an explanation behind the prevalence of credit card debt as discussed in Dezső \& Loewenstein (2012). 
Figure 7: Distribution of subjective ranking today by age, in 2008

Today
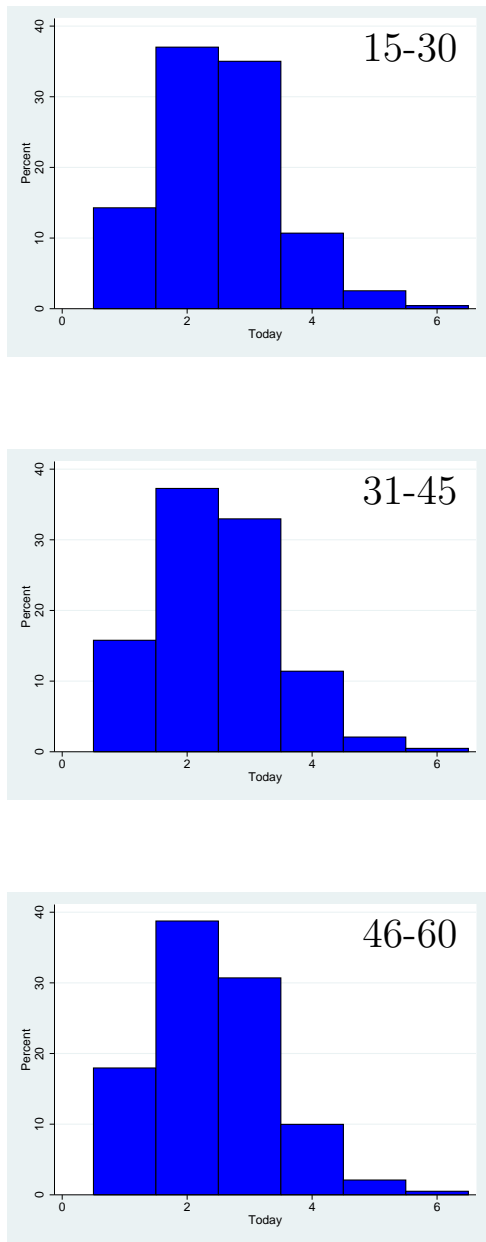

In 2 years
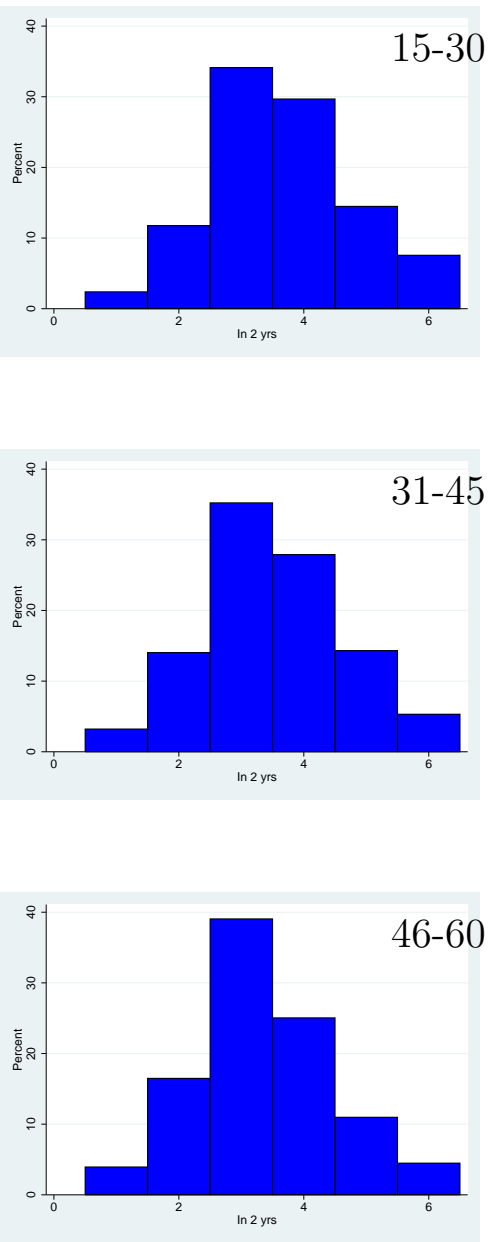

In 5 years
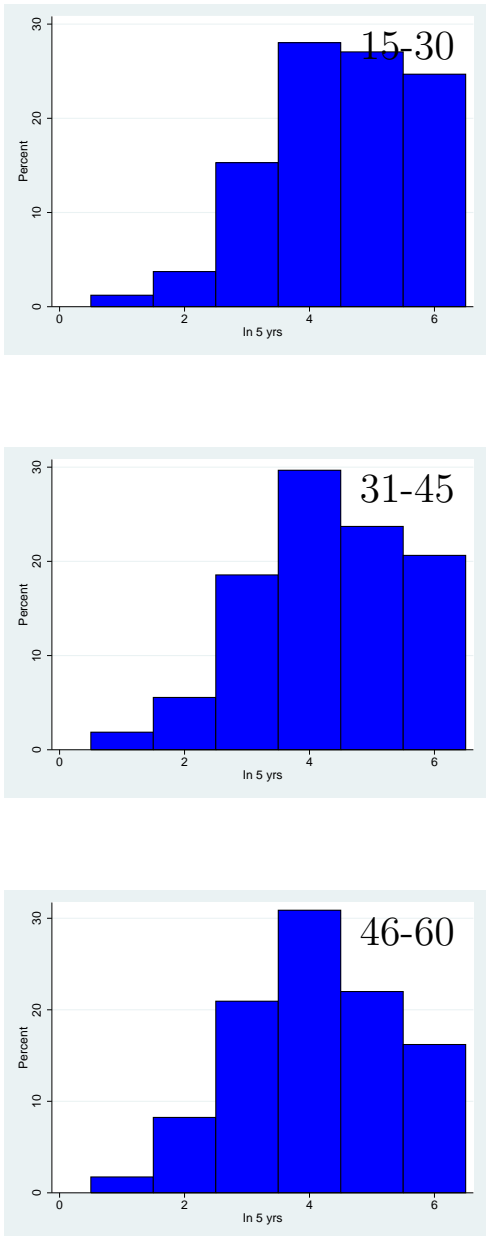

\section{References}

Arabsheibani, G., de Meza, D., Maloney, J., \& Pearson, B. (2000). And a vision appeared unto them of a great profit: evidence of self-deception among the self-employed. Economics Letters, 67(1), pp. 35-41.

Ashraf, N., Karlan, D., \& Yin, W. (2006). Tying Odysseus to the mast: Evidence from a commitment savings product in the Philippines. The Quarterly Journal of Economics, 635-672.

Basu, K. (2011) Hyperbolic discounting and the sustainability of rotational savings arrangements. American Economic Journal: Microeconomics, Vol. 3, No. 4, pp. 143-171.

Basu, K. (2014). Commitment savings in informal banking markets. Journal of Development Economics, 107, 97-111. 
Basu, K. (2016). A behavioral model of simultaneous borrowing and saving. Oxford Economic Papers, 68(4), 1166-1174.

Collins, D. Morduch, J., Rutherford, S. \& O. Ruthven (2009) Portfolios of the Poor. How the World's Poor Live on \$2 a Day. Princeton University Press 2009.

De Meza, D., \& Southey, C. (1996) The borrower's curse: Optimism, finance and entrepreneurship. The Economic Journal, Vol. 106, No. 435, pp. 375-386.

Dezső, L., \& Loewenstein, G. (2012) Lenders' blind trust and borrowers' blind spots: A descriptive investigation of personal loans. Journal of Economic Psychology, Vol. 33, No. 5, pp. 996-1011.

Duflo, E., Kremer, M., \& Robinson, J. (2011) Nudging Farmers to Use Fertilizer: Theory and Experimental Evidence from Kenya. American Economic Review, Vol. 101, No. 6, pp. 2350-90.

Frederick, S., Loewenstein, G., \& O'donoghue, T. (2002) Time discounting and time preference: A critical review. Journal of economic literature, Vol. XL (June 2002), pp. 351-401.

Graham, C., \& M. Hoover (2007) Optimism and poverty in Africa: Adaptation or a means to survival?. Afrobarometer Working Paper No. 76.

Hofmeyr, J. (2013) Africa Rising? Popular Dissatisfaction with Economic Management Despite a Decade of Growth. Afrobarometer Policy Brief No. 2.

Laibson, D. I. (1996) Hyperbolic discount functions, undersaving, and savings policy. Working paper No. w5635. National bureau of economic research.

Loewenstein, G., \& D. Prelec (1992) Anomalies in intertemporal choice: Evidence and an interpretation. The Quarterly Journal of Economics, Vol. 107, No. 2, pp. 573-597.

Noor, J. (2009) Hyperbolic discounting and the standard model: Eliciting discount functions. Journal of Economic Theory, Vol. 144, No. 5, pp. 2077-2083.

Ogaki, M., J.D. Ostry \& C.M. Reinhart (1996) "Saving Behavior in Low- and Middle-Income Developing Countries: A Comparison," IMF Staff Papers, Vol. 43, No. 1, pp. 38-71, March.

Posel, D. R., \& Casale, D. M. (2011). "Relative standing and subjective well-being in South Africa: The role of perceptions, expectations and income mobility." Social Indicators Research, 104(2), 195-223.

South African Reserve Bank (2014) Quarterly Economic Review, December 2014.

South African Reserve Bank (2013) Quarterly Bulletin, September 2013.

Taylor, S. E., \& D.A Armor (1996) Positive illusions and coping with adversity. Journal of personality, Vol. 64, No. 4, pp. 873-898. 
Taylor, S. E., \& J.D. Brown (1988) Illusion and well-being: a social psychological perspective on mental health. Psychological bulletin, Vol. 103, No. 2, pp. 193210.

Taylor, S. E., \& J.D. Brown (1994) Positive illusions and well-being revisited: separating fact from fiction. Psycholigical Bulletin, Vol. 116, No. 1, pp. 21-27.

Thaler, R.H. (1981) Some Empirical Evidence on Dynamic Inconsistency. Economic Letters, Vol. 8, pp. 201-207.

Ubfal, D. (2012) How general are time preferences? Eliciting good-specific discount rates (No. 6774). Discussion Paper series, Forschungsinstitut zur Zukunft der Arbeit.

Wave 3 Data: Southern Africa Labour and Development Research Unit. National Income Dynamics Study 2012, Wave 3 [dataset]. Version 1.2. Cape Town: Southern Africa Labour and Development Research Unit [producer], 2014. Cape Town: DataFirst [distributor], 2014.

Wave 2 Data: Southern Africa Labour and Development Research Unit. National Income Dynamics Study 2010-2011, Wave 2 [dataset]. Version 2.2. Cape Town: Southern Africa Labour and Development Research Unit [producer], 2014. Cape Town: DataFirst [distributor], 2014.

Wave 1 Data: Southern Africa Labour and Development Research Unit. National Income Dynamics Study 2008, Wave 1 [dataset]. Version 5.2. Cape Town: Southern Africa Labour and Development Research Unit [producer], 2009. Cape Town: DataFirst [distributor], 2014.

Wave 3 User Manual: De Villiers, L., Brown, M., Woolard, I., Daniels, R.C., \& Leibbrandt, M, eds. 2013, "National Income Dynamics Study Wave 3 User Manual", Cape Town: Southern Africa Labour and Development Research Unit.

Wave 2 User Manual: Brown, M., Daniels, R.C., De Villiers, L., Leibbrandt, M., \& Woolard, I., eds. 2013, "National Income Dynamics Study Wave 2 User Manual", Cape Town: Southern Africa Labour and Development Research Unit.

Weinstein, N. D. (1980) Unrealistic optimism about future life events. Journal of personality and social psychology, Vol. 39, No. 5, pp. 806-820. 